\title{
Electro-thermal bipolar vessel sealing versus clipping of the inferior mesenteric vessels during minimally invasive proctectomy
}

\author{
Sellado electrotérmico de vasos bipolares versus recorte de los vasos mesentéricos \\ inferiores durante la proctectomía mínimamente invasiva
}

\author{
Mohamed Zuhdy', Islam H. Metwally ${ }^{1 *}$, Ugo Elmore'2, Sameh Roshdy ${ }^{1}$, and Riccardo Rosati \\ ${ }^{1}$ Surgical Oncology Unit, Oncology Center Mansoura University (OCMU), Mansoura, Egypt; ${ }^{2}$ Department of Gastrointestinal Surgery, San Raffaele \\ Scientific Institute, University Vita-Salute, Milan, Italy
}

\begin{abstract}
Introduction: The introduction of new energy vessel sealing devices in minimally invasive proctectomy led to better hemostatic effect, less blood loss, and shorter operating time. At present, the available evidence from literature about the use of electro-thermal bipolar vessel sealers (EBVS) in laparoscopic rectal cancer surgery is weak where most studies are retrospective with non-homogenous patient groups. Methods: This is a retrospective cohort study where 40 rectal cancer patients operated by laparoscopic TME or laparoscopic assisted transanal total mesorectal excision were classified in two groups according to approach of inferior mesenteric vessels ligation (EBVS versus Clipping). Results: The operative time was significantly longer and the blood loss was significantly more in the EBVS group. However, hospital stay, time to oral, time to starting stoma function, and number of retrieved lymph nodes were not significantly affected by the method of vascular control. Conclusion: Both methods for control of vascular pedicle during minimally invasive rectal cancer surgery are safe, as such it is at the discretion of the operating surgeon to which method to use. Prospective well-designed trials are awaited to provide stronger evidence.
\end{abstract}

Key words: Energy devices. Ligasure. Rectal cancer. Minimally invasive surgery. Total mesorectal excision.

\section{Resumen}

Antecedentes: La introducción de nuevos dispositivos de sellado de vasos energéticos en la proctectomía mínimamente invasiva condujo a un mejor efecto hemostático, una menor pérdida de sangre y un tiempo de operación más corto. Actualmente, la evidencia disponible en la literatura sobre el uso de EBVS (electro-thermal bipolar vessel sealers) en cirugía laparoscópica de cáncer rectal es débil, pues la mayoría de los estudios son retrospectivos con grupos de pacientes no homogéneos. Método: Estudio de cohorte retrospectivo con 40 pacientes con cáncer rectal operados por escisión mesorrectal total laparoscópica o asistida por laparoscopia, clasificados en dos grupos según el enfoque de la ligadura de los vasos mesentéricos inferiores (EBVS vs. recorte). Resultados: El tiempo operatorio fue significativamente mayor y la pérdida de sangre fue significativamente mayor en el grupo EBVS. Sin embargo, el método de control vascular no afectó significativamente el tiempo de hospitalización, el tiempo hasta el inicio de la función del estoma ni el número de ganglios linfáticos recuperados. Conclusión: Ambos métodos para el control del pedículo vascular durante la cirugía de cáncer rectal mínimamente invasiva

\section{Correspondence:}

*Islam H Metwally

Geehan Street 
son seguros, por lo que queda a discreción del cirujano el método a utilizar. Se esperan ensayos prospectivos bien diseñados para proporcionar pruebas más sólidas.

Palabras clave: Dispositivos de energía. LigaSure ${ }^{T M}$. Cáncer de recto. Cirugía mínimamente invasiva. Escisión mesorrectal total.

\section{Introduction}

The adoption of minimally invasive techniques in rectal cancer surgery has been show to offer many advantages including less blood loss, earlier recovery of bowel function, shorter hospital stay, earlier return to daily activities, and better post-operative pain scores $^{1,2}$. Thanks to the continuous innovation of laparoscopic instruments, laparoscopic colorectal surgery is being considered feasible nowadays instead of being technically demanding with a steep learning curve in the past ${ }^{3}$.

The standard method of inferior mesenteric vessels ligation during laparoscopic colorectal surgery is either laparoscopic staplers or vascular clips ${ }^{4}$. The introduction of new energy vessel sealing devices led to better hemostatic effect, less blood loss, and shorter operating time utilizing either radiofrequency in electro-thermal bipolar vessel sealers (EBVS), ultrasound in ultrasonic shears or even a combination with conventional bipolar energy 5 .

The advanced EBVS Ligasure $₫$ (Covidien, Mansfield, MA, USA) applies high current low voltage power that when combined with compression by the device jaws leads to collapse of the vessel wall with denaturation of its elastin and collagen that ends in vessel sealing ${ }^{6,7}$. This device can seal vessels up to $7 \mathrm{~mm}$ in diameters and these sealed vessels can withstand a systolic blood pressure 3 times the normal value ${ }^{8}$. The use of laparoscopic staplers or clips to ligate the inferior mesenteric vessels necessitates reloads, which might increase the operative time and costs of surgery. Unlike the EBVS which could also be used in control of bleeding from the omentum, mesentery, or retroperitoneum and to dissect the tissues which is suggested to decrease the instruments traffic ${ }^{9}$.

At present, the available evidence from literature about the use of EBVS in laparoscopic rectal cancer surgery is weak. Most of the studies recruited heterogeneous group of diseases (benign and malignant), heterogeneous types of surgeries (right, left-sided colectomies, and anterior resections), and even heterogeneous approaches to inferior mesenteric vessels ligation (EBVS 5 and $10 \mathrm{~mm}$ sizes, ultrasonic shears, vascular staplers, and clipping). In the present study, we tried to narrow our study population, where we retrospectively focused on operative safety and shortterm outcome of laparoscopic rectal cancer surgery using either Ligasure $₫ 5 \mathrm{~mm}$ or vascular clips to ligate the inferior mesenteric pedicle. We believed that this could attain more relevant results.

\section{Methods}

The present study was designed as a retrospective cohort study where forty rectal cancer patients operated by minimally invasive approaches (laparoscopic assisted or taTME with laparoscopic assistance) in two tertiary centers (Oncology Center Mansoura University, Egypt, and San Raffaele Hospital, Milan Italy) during a period of 25 months (April 2017-May 2019) were recruited. The patients were classified into two groups according to the method of vascular ligation either mechanical ligature group $(n=24)$ or EBVS group $(n=16)$. Demographic, operative, and post-operative data were collected from a prospectively maintained database in both centers. In case of missing data video recordings of the surgeries were reviewed and the operating surgeons were contacted, patients with any missing data were excluded from the study.

In all patients, a medial approach with high tie of the vascular pedicle was applied. The ligation and transection of the inferior mesenteric pedicle were accomplished after placing two clips - either titanium (Fig. 1A and B) or hemoclips (Fig. 2A and B) - proximally using a laparoscopic clip applier and one clip distally (Fig. 1C) then cutting in between in the mechanical ligature group. In the EBVS group Ligasure $₫$ $5 \mathrm{~mm}$ was used to seal the inferior mesenteric vessels after skeletonization of the vessel and visualization of the left ureter. Two device activations were performed proximally (Fig. 3A) and distally (Fig. 3B), and then the vessel was cut by the device's knife in between (Fig. 3C).

Operations were performed by four surgical oncology consultants and a specialist in Oncology Center Mansoura University and three gastrointestinal surgery consultants in San Raffaele hospital. 


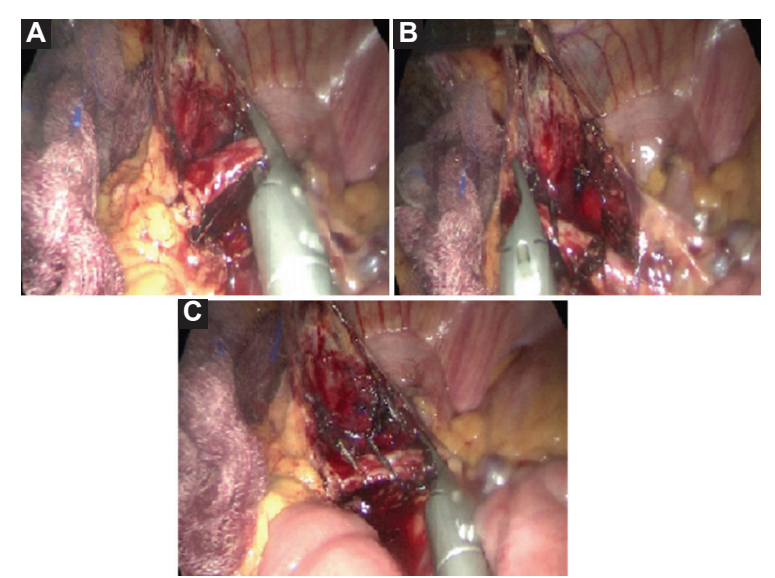

Figure 1. A-C: Controlling of the inferior mesenteric vessels using titanium clips. Proximally 2 clips then distally 1 clip.

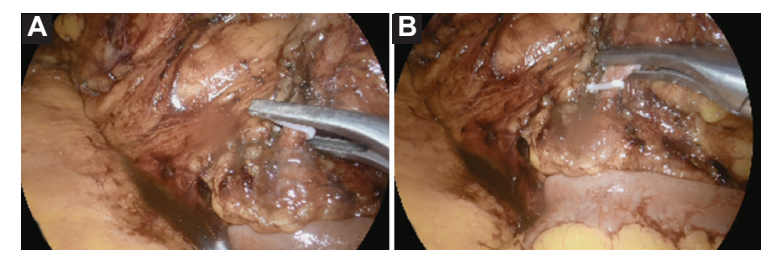

Figure 2. A-B: controlling of the inferior mesenteric vessels using hemoclips.

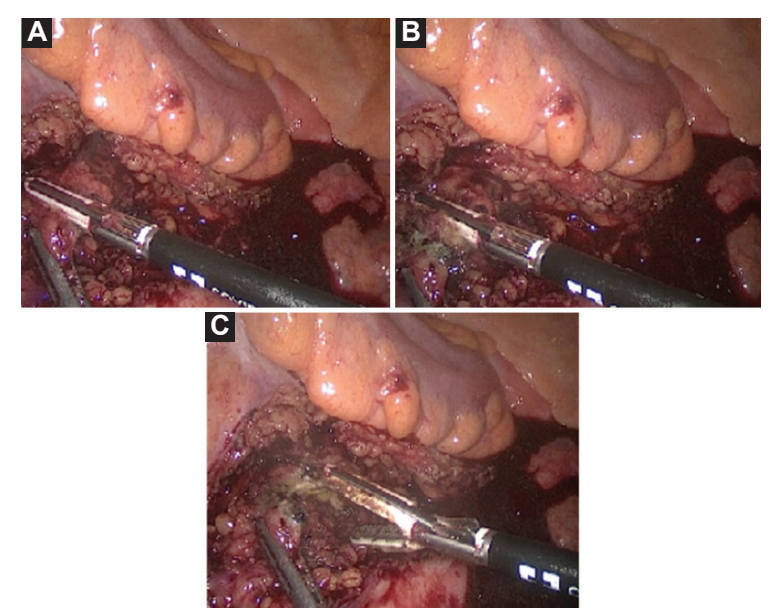

Figure 3. Controlling of inferior mesenteric vessels using ligasure $5 \mathrm{~mm}$. A: proximal bite. B: distal bite. C: cutting in between.

The primary outcome of the study was the operative feasibility and safety of both techniques through comparing several variables: operative time (minutes), estimated blood loss (milliliters), the need for blood transfusion, operative complications, conversion, and post-operative complications (assessed by ClavienDindo Score). The secondary outcome included the short-term oncologic results in the form of: lymph node harvest, circumferential and longitudinal margins assessment, quality of total mesorectal excision, and recurrence events.

\section{Statistical analysis}

Analysis of the patients' data was performed using SPSS (version 22). Naturally, distributed parameters were presented as mean and standard deviation; otherwise data are presented as median and range or percentage. Categorical variables were compared using Chi-square, while Mann-Whitney and Student $t$ tests were used for parametric data.

\section{Results}

Forty cases were enrolled in this study. The mean age of the study patients was 53.2. Male predominates with 24 cases versus 16 female patients. The mean BMI of the study group was 28.2 (overweight). All cases were low to mid rectal cancer except for one case of upper rectal cancer.

In this study, 22 patients underwent laparoscopic total mesorectal excision (LTME), while 18 patients underwent transanal total mesorectal excision (taT$M E)$. Thirty-four patients (85\%) received neoadjuvant therapy before proctectomy.

In 14 cases, advanced bipolar, namely, Ligasure $\AA$ was employed in vascular control, in contrast to 26 patients where clipping was used for vascular control.

All cases underwent stoma, all loop ileostomy except three terminal colostomies. Morbidities occurred in 13 case, representing $32.5 \%$ of cases with one case of peri-operative mortality because of septic shock after necrotizing fasciitis of the Pfannenstiel incision (Table 1).

Patients were divided into two groups according to the method of vascular pedicle control; Group 1 used advanced bipolar (EBVS group), while Group 2 used vascular clips (clip group). The statistical comparison of the two groups regarding basic epidemiologic, operative, and pathologic data revealed insignificant difference except for the BMI which was significantly higher in the EBVS group (mean difference 7.5) (Table 2).

The two study groups were compared regarding operative and oncologic short outcomes and morbidity, as shown in table 3. The operative time was significantly longer (mean difference $103 \mathrm{~min}$ ) and the 
Table 1. Basic data of the patients included in the study

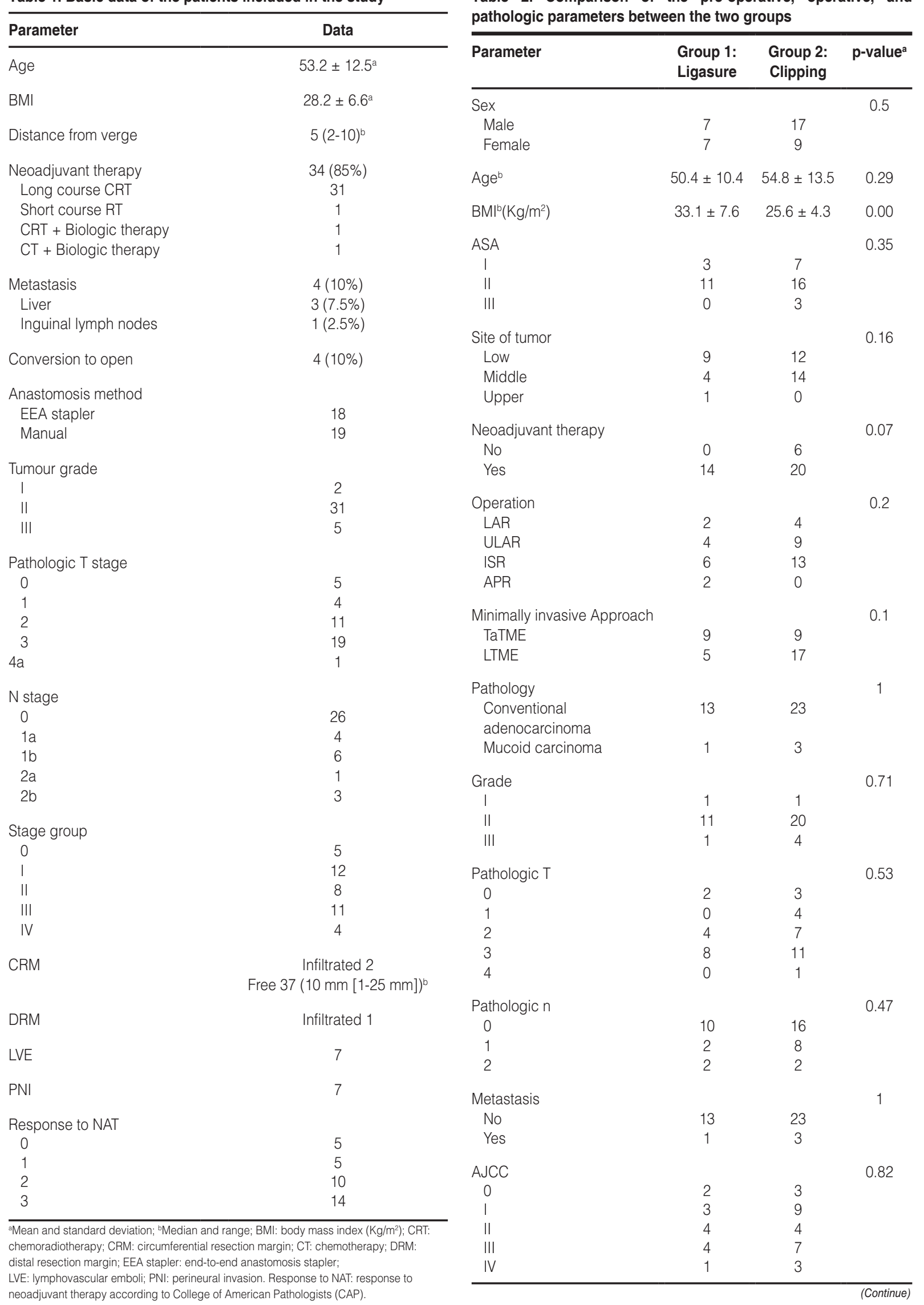

Table 2. Comparison of the pre-operative, operative, and pathologic parameters between the two groups 
Table 2. Comparison of the pre-operative, operative, and pathologic parameters between the two groups (Continued)

\begin{tabular}{|c|c|c|c|}
\hline Parameter & $\begin{array}{l}\text { Group 1: } \\
\text { Ligasure }\end{array}$ & $\begin{array}{l}\text { Group 2: } \\
\text { Clipping }\end{array}$ & p-value \\
\hline $\begin{array}{l}\text { CRM } \\
\text { Free } \\
\text { Infiltrated }\end{array}$ & $\begin{array}{c}12 \\
1\end{array}$ & $\begin{array}{c}25 \\
1\end{array}$ & 1 \\
\hline $\begin{array}{l}\text { DRM } \\
\text { Free } \\
\text { Infiltrated }\end{array}$ & $\begin{array}{c}13 \\
1\end{array}$ & $\begin{array}{c}26 \\
0\end{array}$ & 0.35 \\
\hline $\begin{array}{l}\text { LVE } \\
\text { No } \\
\text { Yes }\end{array}$ & $\begin{array}{c}12 \\
2\end{array}$ & $\begin{array}{c}21 \\
5\end{array}$ & 1 \\
\hline $\begin{array}{l}\text { PNI } \\
\text { No } \\
\text { Yes }\end{array}$ & $\begin{array}{c}10 \\
4\end{array}$ & $\begin{array}{c}23 \\
3\end{array}$ & 0.21 \\
\hline $\begin{array}{l}\text { Response to NAC therapy } \\
\text { (CAP grade) } \\
0 \\
1 \\
2 \\
3\end{array}$ & $\begin{array}{l}2 \\
2 \\
3 \\
7\end{array}$ & $\begin{array}{l}3 \\
3 \\
7 \\
7\end{array}$ & 0.81 \\
\hline $\begin{array}{l}\text { Quality of TME } \\
\text { Incomplete } \\
\text { Near complete } \\
\text { Complete }\end{array}$ & $\begin{array}{c}0 \\
3 \\
11\end{array}$ & $\begin{array}{c}1 \\
3 \\
22\end{array}$ & 0.56 \\
\hline $\begin{array}{l}\text { Adjuvant therapy } \\
\text { No } \\
\text { Yes }\end{array}$ & $\begin{array}{c}1 \\
10\end{array}$ & $\begin{array}{c}6 \\
18\end{array}$ & 0.39 \\
\hline
\end{tabular}

${ }^{a} p$ value is considered significant if $\otimes 0.05 \mathrm{~b}$ Mean and standard deviation;

AJCC: American Joint Committee on Cancer; ASA: American Society of

Anesthesiologists; APR: Abdomino-perineal resection; BMI: body mass index

$\left(\mathrm{Kg} / \mathrm{m}^{2}\right)$; CRM: circumferential resection margin; LAR: low anterior resection; DRM: distal

resection margin; ISR: intersphincteric resection; LTME: laparoscopic total mesorectal

excision; LVE: Iymphovascular emboli; PNS: perineural spread; ; TaTME: trans-anal total

mesorectal excision; ULAR: ultralow anterior resection. Response to NAT: response to

neoadjuvant therapy according to College of American Pathologists (CAP).

blood loss was significantly more in the EBVS group. However, hospital stay, time to oral, time to starting stoma function and number of retrieved lymph nodes were not significantly affected by the method of vascular control. Moreover, complications related to autonomic nerve injury (bladder dysfunction, impotence, and retrograde ejaculation) occurred in two cases in the clip group and nil in the EBVS group.

\section{Discussion}

The growing adoption of minimally invasive techniques in colorectal cancer surgery has led to an increasing need for safer, more efficient, reliable hemostasis, and tissue dissection ${ }^{10}$. Recent advances in technology of laparoscopic surgical instrumentation made laparoscopic colorectal surgery more feasible ${ }^{3}$.

There are several available options for control of the inferior mesenteric vascular pedicle. These include laparoscopic vascular staplers which are disposable and require reloads, clip appliers which may be single or multi-fire, disposable or reusable, and energybased devices. The last two options are more commonly adopted by surgeons, but more skills might be needed in vascular clipping to avoid bleeding and longer operative duration?.

Ligasure $5 \mathrm{~mm}$ is an advanced EBVS which applies the main principle of conversion of electrical energy to mechanical energy to thermal energy to ensure vessel sealing without the risk of passage of electric current through the tissue ${ }^{5}$. In addition, it is a multifunctional device with blunt non-traumatic jaws which is considered an important advantage in complex laparoscopic colorectal surgery. This is because it allows the surgeon to use it throughout the surgery with efficient hemostatic ability which avoids the need for changing instruments and minimizes instruments traffic through the different steps of surgery ${ }^{11}$. The advantage of adding a cutting device in the Ligasure also minimizes the instrument traffic and this should have an impact on operative time and surgical costs ${ }^{12}$.

Advanced EBVS devices as Ligasure were approved by the United States food and drug administration to seal blood vessels up to $7 \mathrm{~mm}$ in diameter ${ }^{13}$. The duration needed for sealing a blood vessel is $10 \mathrm{~s}$, this seal can withstand systolic blood pressure 3 times the normal value ${ }^{14}$. It is well known that the burst pressure for vascular stapling or clipping is higher than EBVS, but this is clinically irrelevant provided that both are above the physiologic level ${ }^{15}$.

In the present study, statistically significant higher mean operative time (353.6 vs.250.6 min, $p=0.00$ ) and median blood loss ( 500 vs. 200 milliliters, $p=0.00$ ) were reported in the EBVS group than in the clipping group. These results are different from those reported by Marcello et al. where they compared both approaches in cases of right, left colectomies, sigmoidectomies, and total colectomies. They found higher mean operative time and blood loss in the clipping group than the EBVS group, but in his study the differences were not statistically significant. They used Ligasure $10 \mathrm{~mm}$ for vascular pedicle ligation in the EBVS group, and they included benign and malignant cases $^{9}$. This can be explained by the higher BMI in the EBVS group in the current study; this coincides with a meta-analysis adopted by Fung et al., who 
Table 3. Comparison of operative outcome and perioperative complications

\begin{tabular}{|c|c|c|c|}
\hline Outcome & Group 1: Ligasure & Group 2: Clipping & $p$-value ${ }^{a}$ \\
\hline Conversion to open & & & 0.11 \\
\hline No & 11 & 25 & \\
\hline Yes & 3 & 1 & \\
\hline Operative time ${ }^{b}$ (min) & $353.6 \pm 65.7$ & $250.6 \pm 65.3$ & 0.00 \\
\hline Blood loss ${ }^{c}($ milliliter $)$ & $500(220-650)$ & $200(50-750)$ & 0.00 \\
\hline Time to oral (days) & $2.5(1-4)$ & $2(2-4)$ & 0.75 \\
\hline Function stoma ${ }^{c}$ (days) & $2(1-3)$ & $2(2-4)$ & 0.65 \\
\hline Hospital stay & $7.5(3-18)$ & $7(4-19)$ & 0.81 \\
\hline LN harvest & $9(3-17)$ & $12.5(2-42)$ & 0.21 \\
\hline LN infiltrated & $0(0-14)$ & $0(0-15)$ & 0.68 \\
\hline Peri-operative complications (CD) & & & 0.26 \\
\hline । & 1 & 0 & \\
\hline$\|$ & 1 & 4 & \\
\hline IIla & 3 & 2 & \\
\hline $\mathrm{lllb}$ & 0 & 1 & \\
\hline V & 1 & 0 & \\
\hline Functional nerve related complications & & & 0.53 \\
\hline No & 14 & 24 & \\
\hline Bladder dysfunction and impotence & 0 & 1 & \\
\hline Retrograde ejaculation & 0 & 1 & \\
\hline Recurrence events & & & 1 \\
\hline No & 12 & 23 & \\
\hline Yes & 2 & 3 & \\
\hline
\end{tabular}

ap value is considered significant if $\otimes 0.05$; 'Mean and standard deviation Median and range; $L N$ : lymph node. Clavien Dindo's scale

reported increased operative time and increased incidence of peri-operative complications including more estimated blood loss in obese patients who underwent laparoscopic colorectal surgery ${ }^{16}$. Furthermore, the operating surgeons may have chosen EBVS rather than clipping in difficult prolonged procedures in trial to cut down the operative time.

Another merit of advanced EBVS is the pulsatile electrical energy delivery along with computer-controlled tissue feedback response which decreases the risk of lateral thermal spread. Moreover, it avoids the possibility of high tissue temperature, lateral thermal spread, tissue charring, and adhesion to the instrument jaws thanks to the automatic shut-down feature once the desired tissue sealing was accomplished ${ }^{5}$.

In their study, Trilling et al. reported comparable minor complications events (CD I-II) in both groups of energy devices or clipping of inferior mesenteric vessels during laparoscopic sigmoidectomy for diverticulitis. Major events (CD III-V) were reported more in mechanical ligature group, but these results were statistically insignificant. Conversion to open was not significantly higher in the mechanical ligature group ${ }^{17}$. In our study, minor complications were insignificantly higher in the clipping group, while the major complications were nearly comparable in both groups. Conversion to open was insignificantly higher in the EBVS group.

It is worth mentioning that every energy device has its own advantages and disadvantages. This could explain the lack of strong evidence about their use. Moreover, factors such as personal preference, surgical learning curve and training, availability, cost of the energy devices, and familiarity of the surgeon with them could explain the contradictory results and weak evidence from the previously reported studies ${ }^{18}$.

The present study has some limitations such as the retrospective nature, non-reporting of long-term functional results, and the recruitment of patients operated by heterogeneous group of surgeons in two different hospitals which could have an impact on the reported results due to difference in surgical technique or learning curve. Moreover, significantly higher BMI was reported in the EBVS group which could have affected 
some operative results as operative time and blood loss. To sum up, we tried to present better quality of reported results through narrowing of the study population focusing on surgery for rectal cancer patients and reporting data on oncologic outcome which was deficient in previous studies.

\section{Conclusion}

Controlling of the inferior mesenteric vessels using EBVS and clipping has comparable results regarding safety, feasibility, and short-term oncologic outcomes. It mainly depends on surgeon's preference and experience which method to choose for control of vascular pedicle during minimally invasive rectal cancer surgery. Prospective well-designed trials are awaited to provide stronger evidence regarding the best approach for colorectal vascular pedicle ligation.

\section{Conflicts of interest}

The authors have no conflicts to declare.

\section{Funding}

The authors did not receive funding in relation to this article.

\section{Ethical disclosures}

Protection of human and animal subjects. The authors declare that the procedures followed were in accordance with the regulations of the relevant clinical research ethics committee and with those of the Code of Ethics of the World Medical Association (Declaration of Helsinki).

Confidentiality of data: The authors declare that they have followed the protocols of their work center on the publication of patient data.

Right to privacy and informed consent: The authors have obtained the written informed consent of the patients or subjects mentioned in the article. The corresponding author is in possession of this document.

\section{References}

1. Martin S, Heeney A, Pierce C, O'Connell P, Hyland J, Winter DC. Use of an electrothermal bipolar sealing device in ligation of major mesenteric vessels during laparoscopic colorectal resection. Tech Coloproctol. 2011;15:285-9.

2. Lujan J, Valero G, Biondo S, Espin E, Parrilla P, Ortiz H. Laparoscopic versus open surgery for rectal cancer: results of a prospective multicentre analysis of 4,970 patients. Surg Endosc. 2013;27:295-302.

3. Tou S, Malik AI, Wexner SD, Nelson RL. Energy source instruments for laparoscopic colectomy. Cochrane Database Syst Rev. 2011;5:CD007886.

4. Gezen C, Altuntas YE, Kement M, Vural S, Civil O, Okkabaz N, et al. Complete versus partial mobilization of splenic flexure during laparoscopic low anterior resection for rectal tumors: a comparative study. J Laparoendosc Adv Surg Tech A. 2012;22:392-6.

5. Lyons SD, Law KS. Laparoscopic vessel sealing technologies. J Minim Invasive Gynecol. 2013;20:301-7.

6. Reyes DA, Brown SI, Cochrane L, Motta LS, Cuschieri A. Thermal fusion: effects and interactions of temperature, compression, and duration variables. Surg Endosc. 2012;26:3626-33.

7. Wallwiener CW, Rajab TK, Zubke W, Isaacson KB, Enderle M, Schäller D, et al. Thermal conduction, compression, and electrical current an evaluation of major parameters of electrosurgical vessel sealing in a porcine in vitro model. J Minim Invasive Gynecol. 2008;15:605-10.

8. Kennedy J, Stranahan P, Taylor K, Chandler J. High-burst-strength, feedback-controlled bipolar vessel sealing. Surg Endosc. 1998;12:876-8.

9. Marcello P, Roberts P, Rusin L, Holubkov R, Schoetz D. Vascular pedicle ligation techniques during laparoscopic colectomy. A prospective randomized trial. Surg Endosc. 2006;20:263-9.

10. Suhardja TS, Norhadi S, Ee E, Hodgkins B. Comparison of the thunderbeat and other energy devices in laparoscopic colorectal resection: a single-center experience. $\mathrm{J}$ Laparoendosc Adv Surg Tech A 2018;28:1417-21.

11. Grieco M, Apa D, Spoletini D, Grattarola E, Carlini M. Major vessel sealing in laparoscopic surgery for colorectal cancer: a single-center experience with 759 patients. World J Surg Oncol. 2018;16:101.

12. Munro MG. Economics and energy sources. J Minim Invasive Gynecol. 2013;20:319-27.

13. Newcomb WL, Hope WW, Schmelzer TM, Heath JJ, Norton HJ, Lincourt $A E$, et al. Comparison of blood vessel sealing among new electrosurgical and ultrasonic devices. Surg Endosc. 2009;23:90-6.

14. Lamberton GR, Hsi RS, Jin DH, Lindler TU, Jellison FC, Baldwin DD. Prospective comparison of four laparoscopic vessel ligation devices. $J$ Endourol. 2008;22:2307-12.

15. Harold K, Pollinger H, Matthews B, Kercher K, Sing R, Heniford B. Comparison of ultrasonic energy, bipolar thermal energy, and vascular clips for the hemostasis of small-, medium-, and large-sized arteries. Surg Endosc. 2003;17:1228-30.

16. Fung A, Trabulsi N, Morris M, Garfinkle R, Saleem A, Wexner SD, et al. Laparoscopic colorectal cancer resections in the obese: a systematic review. Surg Endosc. 2017;31:2072-88.

17. Trilling B, Riboud R, Abba J, Girard E, Faucheron JL. Energy vessel sealing systems versus mechanical ligature of the inferior mesenteric artery in laparoscopic sigmoidectomy. Int J Colorectal Dis. 2016; 31:903-8.

18. Sankaranarayanan G, Resapu RR, Jones DB, Schwaitzberg S, De S. Common uses and cited complications of energy in surgery. Surg Endosc. 2013;27:3056-72. 